\title{
PESQUISA-AÇÃO E EDUCAÇÃO: COMPARTILHANDO PRINCÍPIOS NA CONSTRUÇÃO DE CONHECIMENTOS E NO FORTALECIMENTO COMUNITÁRIO PARA O ENFRENTAMENTO DE PROBLEMAS
}

\author{
RENATA FERRAZ DE TOLEDO* \\ Pedro Roberto Jacobi*
}

RESUMO: O presente trabalho objetiva promover uma reflexão sobre a metodologia da pesquisa-ação quanto aos seus princípios, aplicação e contribuições para a área educacional. Caracterizada pelo envolvimento de grupos sociais no processo de tomada de decisões, a pesquisa-ação, assim como outras metodologias participativas, surge diante da insatisfação para com métodos clássicos de pesquisa. Remete ainda à necessidade de promover maior articulação entre a teoria e a prática na produção do conhecimento e solução de problemas. Para enriquecer a discussão, de forma complementar, será apresentado um panorama do desenvolvimento da pesquisa-ação na área educacional, a partir de revisão bibliográfica.

Palavras-chave: Pesquisa-ação. Diálogo de saberes. Participação.

\section{ACTION RESEARCH AND EDUCATION:}

\section{SHARING BASIC KNOWLEDGE AND COMMUNITY EMPOWERMENT}

\section{TO FACE PROBLEMS}

\begin{abstract}
This paper aims to promote a reflection on the methodology of action research and on its principles, application and contributions to the education field. Action research is characterized by the involvement of social groups in decision-making, as well as other participatory methods, it emerges from dissatisfaction with traditional methods of research. This type of research also refers to the need to promote a better coordination between theory and practice in knowledge production and troubleshooting. To enrich the discussion, in a complementary way, it presents an overview of the action research development in education from a literature review.
\end{abstract}

Key words: Action research. Knowledge dialogue. Participation.

\footnotetext{
* Pós-doutoranda na Faculdade de Educação da Universidade de São Paulo (USP). E-mail: renataft@usp.br

** Livre docente em Educação e professor titular da Faculdade de Educação da Universidade de São Paulo (USP). E-mail: prjacobi@usp.br
} 
LA RECHERCHE-ACTION ET L'ÉDUCATION: PARTAGE DES PRINCIPES DANS LA CONSTRUCTION DES CONNAISSANCES ET DANS LE RENFORCEMENT DE LA COMMUNAUTÉ POUR FAIRE FACE A DES PROBLÈMES

RÉSUMÉ: Ce document vise à promouvoir une réflexion sur la méthodologie de la recherche-action par rapport à ses principes, applications et contributions au secteur de l'éducation. Caractérisée par l'implication des groupes sociaux dans le processus de la prise de décision, la recherche-action, ainsi que d'autres méthodes participatives, émergent de l'insatisfaction envers les méthodes traditionnelles de recherche. La recherche-action se réfère également à la nécessité de promouvoir une plus grande coordination entre la théorie et la pratique dans la production de connaissances et à la solution des problèmes. Pour enrichir le débat, de manière complémentaire, cet article présente un panorama du développement de la recherche-action dans l'éducation, à partir de la révision de la littérature.

Mots-clés: La recherche-action. Le dialogue des savoirs. La participation.

\section{Introdução}

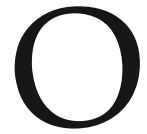

presente trabalho, constituído como um estudo teórico, objetiva analisar a metodologia da pesquisa-ação quanto aos seus princípios, bem como sua aplicação e contribuições para a área da educação. Inicialmente, propõe-se uma reflexão sobre sua origem no contexto de metodologias participativas, seus princípios norteadores e características referentes a sua estrutura organizacional, enfatizando-se seu papel na produção de saberes e no fortalecimento comunitário para o enfrentamento de problemas. Em seguida, baseado em uma revisão bibliográfica, será apresentado e discutido um breve panorama do desenvolvimento da referida metodologia na área educacional, analisando-se desafios para sua efetivação e possíveis contribuições a esse campo do conhecimento.

\section{Pesquisa-ação: origem, princípios e organização}

Metodologias de pesquisa de caráter participativo ganham repercussão mundial tanto na área científica como no campo político, a partir do Primeiro Simpósio Mundial sobre Pesquisa Participante, realizado em Cartagena, Colômbia, em 1977 (FALS BORD A, 1986), e fundamentam-se na preocupação de garantir a participação ativa dos grupos sociais no processo de tomada de decisões sobre assuntos que lhes dizem respeito, com vistas à transformação social, não se tratando, portanto, de uma simples consulta popular, mas sim do envolvimento dos sujeitos da pesquisa em um processo de reflexão, análise da realidade, produção de conhecimentos e enfrentamento dos problemas. 
Pode-se dizer que o surgimento de metodologias de pesquisa participativa relaciona-se, principalmente, a uma insatisfação com paradigmas e métodos de pesquisa clássicos e, no caso da pesquisa-ação em particular, remete não só a necessidade de envolver diretamente os grupos sociais na busca de soluções para seus problemas, mas também de promover maior articulação entre a teoria e a prática na produção de novos saberes (LEWIN, 1946; CARR; KEMMIS, 1986; THIOLLENT, 2011; BARBIER, 2002; EL AND ALOUSSI, 2004).

Neste contexto de insatisfação, outros movimentos como a Ciência Pós-Normal (RAVETZ, 2004), a Abordagem Ecossistêmica (LEBEL, 2003), a Aprendizagem Social (PAHL WOST; HARE, 2004), entre outros, fundamentados da mesma maneira pelo pré-requisito da participação e pelo diálogo e produção de saberes entre os diversos stakeholders (pesquisadores, sujeitos e tomadores de decisão), têm se mostrado como potencialmente eficazes diante de situações complexas a serem enfrentadas nas diversas áreas do conhecimento.

Entre os principais precursores da pesquisa-ação, Kurt Lewin é o mais referenciado (ADELMAN, 1993; THIOLLENT, 2011; BARBIER, 2002; MORIN, 2004), com seus estudos organizacionais e educacionais realizados em um contexto de pós-guerra, em 1946, quando trabalhava para o governo norte-americano. Lewin mostrava-se interessado em contribuir para a elevação da autoestima de grupos minoritários e, por meio da pesquisa-ação, sustentada pela comunicação e cooperação entre pares, procurou fortalecer as relações sociais destes grupos (ADELMAN, 1993; FRANCO, 2005).

Para alguns autores (THIRION, 1980; GOYETTE; LESSARD-HÉBERT, 1993) citados por El Andaloussi (2004), entretanto, a pesquisa-ação tem sua origem em trabalhos anteriores, como os desenvolvidos por Dewey, em 1929, que ressaltavam a importância de pesquisas sobre a prática escolar e a obtenção de melhores resultados a partir do envolvimento dos sujeitos nesse processo. De qualquer maneira, são inegáveis as contribuições de Lewin na formulação e sistematização da chamada action research no quadro da psicologia social.

$\mathrm{Na}$ área educacional, a pesquisa-ação tem ainda forte inspiração nos trabalhos desenvolvidos por Stephen Corey, na década de 1950, sobre experimentação do currículo procurando, da mesma maneira, incorporar à prática educativa resultados identificados por meio de pesquisa. Para Corey (1979, p. 298), “ouvir dizer o que devemos fazer é muito diferente de descobrir pessoalmente o que devemos fazer".

Na América Latina, não só a pesquisa-ação, mas as pesquisas participantes de maneira geral surgem entre as décadas de 1960 e 1970 nas experiências de Paulo Freire, Carlos Rodrigues Brandão, Danilo Strech, entre outros, preocupados 
também com a participação dos grupos sociais considerados excluídos da tomada de decisões para a solução de problemas coletivos, tendo, portanto, um conteúdo bastante politizado. No caso de Paulo Freire, em especial, ao se analisar seus postulados sobre a importância da reflexão crítica dos sujeitos sobre suas práticas e da problematização da realidade para seu enfrentamento, fica evidente a presença de seus pressupostos teórico-metodológicos na consolidação da pesquisa-ação, principalmente no campo da educação. Pode-se dizer ainda que o desenvolvimento desta modalidade de pesquisa intensificou-se fortemente no Brasil entre as décadas de 1980 e 1990 com as obras de René Barbier ${ }^{1}$ e Michel Thiollent, ${ }^{2}$ que são, até o presente, amplamente referenciadas.

Aproximando-se ainda do pensamento de Paulo Freire e contribuindo para o fortalecimento da pesquisa-ação na educação estão as ideias de Laurence Stenhouse, John Elliot, Wilfred Carr e Stephen Kemmis, valorizando a postura investigativa do professor para melhorar sua prática (COSTA, 1991). Carr e Kemmis (1986) preconizam ainda o papel da pesquisa-ação para desencadear mudanças nas políticas e práticas institucionais que sustentam a educação.

Assim, ao posicionar-se como um instrumento de investigação e ação à disposição da sociedade, a pesquisa-ação exerce também uma função política, oferecendo subsídios para que, por meio da interação entre pesquisadores e atores sociais implicados na situação investigada, sejam encontradas respostas e soluções capazes de promover a transformação de representações e mobilizar os sujeitos para ações práticas.

Na pesquisa-ação as intervenções e a produção do conhecimento se interrelacionam. Nesse sentido, Thiollent (2011) recomenda, sempre que possível, um equilíbrio na definição de objetivos práticos, que conduzirão às soluções, e de objetivos de conhecimento, como a identificação de representações, habilidades, entre outros aspectos, que contribuirão, por sua vez, para esclarecer a problemática em evidência e melhor conduzir as ações transformadoras. Podem ser definidos, portanto, objetivos mais instrumentais, voltados para a resolução de um problema prático; e objetivos educacionais, voltados para a tomada de consciência e para a produção de conhecimentos considerados relevantes não apenas para o grupo investigado. Ressalta ainda o autor que, com maior amadurecimento metodológico e o devido respeito aos contextos socioculturais, esses objetivos podem e devem ser alcançados simultaneamente e que a ação deverá ser definida em função dos interesses e das necessidades encontradas, sendo que todas as partes envolvidas na situação investigada devem ser consultadas.

Sobre esse aspecto, Pimenta (2005) considera que na pesquisa-ação os sujeitos envolvidos em determinada problemática constituem um grupo com objetivos 
comuns, no qual assumem papéis diversos, inclusive o de pesquisadores. Para Tripp (2005), para que a participação seja positiva, a proposta de pesquisa-ação deve: tratar de assuntos de interesse mútuo; basear-se em um compromisso compartilhado de realização da pesquisa; permitir que todos os envolvidos participem ativamente da forma que desejarem; partilhar o quanto for possível o controle sobre os processos da pesquisa; produzir uma relação de custo-benefício igualmente benéfica para todos; e estabelecer procedimentos de inclusão para decisões relativas à justiça entre os participantes.

Flicker (2008), por sua vez, ao analisar os benefícios e beneficiários de um projeto participativo, conclui sobre a existência de dois grupos de beneficiários: pesquisadores e diferentes stakeholders. Para a autora, projetos dessa natureza podem trazer benefícios tangíveis e intangíveis para aqueles diretamente envolvidos, bem como para a comunidade como um todo, mas alerta que estes não são, na maioria dos casos, equitativamente distribuídos.

Ainda sobre o caráter participativo, List (2006), na tentativa de distinguir diferentes formas de envolvimento dos sujeitos, apresenta uma escala com sete níveis, que vai desde o nível 1 - cooptação/manipulação (manipulative co-option), passando pelo nível 6 - aprendizado interativo e colaborativo (interative co-learning) e, finalmente, o nível 7 - automobilização e empoderamento (self-mobilization and empowerment).

Na pesquisa-ação, em particular, pode-se dizer que para sua verdadeira efetivação a participação não pode limitar-se a uma simples divulgação de informações, ou ainda a uma consulta popular, mas implica uma postura proativa no processo de tomada de decisões e deve ocorrer, portanto, a partir do nível 6 (aprendizado interativo e colaborativo) em direção ao nível 7 (automobilização e empoderamento), ou seja, ao mesmo tempo que requer a mobilização social e a construção de conhecimentos sobre o tema, ao se concretizar, oferece um processo de aprendizagem mútua e de fortalecimento comunitário.

No tocante a organização da pesquisa-ação, Lewin (1946) considera três fases fundamentais desenvolvidas de forma semelhante a um espiral cíclico: 1) planejamento (planning), que envolve o conhecimento e reconhecimento da situação; 2) ação (action); e 3) encontro de fatos (fact-finding) sobre os resultados da ação, os quais devem ser incorporados na fase seguinte de retomada do planejamento e assim sucessivamente. Dessa forma, por meio desses espirais, as ações tornam-se cada vez mais ajustadas às necessidades coletivas.

Assim, a metodologia da pesquisa-ação é considerada um sistema aberto, isso porque diferentes rumos podem ser tomados no decorrer do seu desenvolvimento em função das demandas encontradas. Inicia-se evidentemente com um 
planejamento. Porém, conforme afirma Thiollent (2011), há um ponto de partida, que é a fase exploratória, e um ponto de chegada, referindo-se à divulgação dos resultados, mas no intervalo haverá uma multiplicidade de caminhos em função das diferentes situações diagnosticadas ao longo do processo.

Neste contexto, o papel do pesquisador deve ser o de oferecer subsídios que propiciem a participação dos atores sociais envolvidos em todas as etapas e assegurar o rigor metodológico, o qual favorecerá o cumprimento dos objetivos propostos (instrumentais, educacionais, científicos, entre outros).

Por constituir-se dessa forma, o grau de cientificidade da pesquisa-ação é alvo de críticas desde o seu surgimento. Para alguns autores, a ciência é um produto exclusivo de métodos clássicos de pesquisa, como os positivistas. E, de fato, analisando-se dessa forma, as características da pesquisa-ação não permitem que esta seja enquadrada nos modelos experimentais convencionais. Porém, conforme destaca Thiollent (op. cit.), sem as ideias de ciência e de racionalidade corre-se o risco da pesquisa-ação cair no irracionalismo - associado ao obscurantismo e às manipulações de toda ordem. Pode-se optar por instrumentos de pesquisa dialógicos, experimentar situações reais, onde as variáveis não são isoláveis, intervir conscientemente no processo, sem por isso abandonar a preocupação científica. O autor completa que pesquisas convencionais e pesquisas alternativas apenas se utilizam de soluções e raciocínios diferentes.

Vale destacar ainda a opinião de Zuñiga (1981) sobre o caráter científico da pesquisa-ação, associado a sua função política e de transformação social. Afirma o autor que ela é considerada de interesse científico somente quando é inovadora, do ponto de vista sociopolítico e ao colocar o controle do saber nas mãos dos grupos e das coletividades que expressam uma aprendizagem coletiva, tanto na sua tomada de consciência, como no seu comprometimento com a ação coletiva, mas deve ser denunciada quando se torna um instrumento nas mãos do poder dominante.

\section{Aprendizagem coletiva, intervenção e produção do conhecimento na pesquisa-ação}

A ação desencadeada pelo processo de pesquisa-ação, conforme já mencionado, pode ser de caráter prático, educativo, comunicativo, político, cultural etc., e ser originada e desenvolvida no decorrer do processo de pesquisa, em função das necessidades encontradas, e não ao seu término, como ocorre usualmente em outros tipos de pesquisa. Dessa forma, na medida em que os atores sociais se envolvem diretamente em uma ação que contribuirá para a solução de seus problemas, supera-se a passividade e, conforme afirma El Andaloussi (2004), essa modalidade 
de pesquisa propicia a redução das distâncias entre pesquisadores, tomadores de decisão e atores, não se tratando, portanto, de uma simples ação experimental a serviço da pesquisa e nem de uma ação para resolver exclusivamente um problema sem a investigação de suas causas e consequências. A pesquisa demanda uma ação, que por sua vez demandará novas pesquisas, e essa interrelação será a base para uma possível transformação social.

Ao investigar e agir, pesquisadores e atores sociais desenvolvem um processo de aprendizagem coletiva, já que os resultados encontrados no decorrer do processo oferecerão novos ensinamentos a todos. Para Giovanni (1994), as relações estabelecidas no decorrer de uma pesquisa-ação assumem características didáticas ao favorecer a investigação, o ensino e a aprendizagem, mas alerta a autora que este processo não é espontâneo, devendo ser trabalhado ao longo do seu desenvolvimento. Tozoni-Reis (2007) reforça ainda que a articulação entre a pesquisa e a educação é uma das características mais importantes da pesquisa-ação, onde a troca de conhecimentos possibilitada pelo processo de participação ocorrerá não apenas por meio dos conhecimentos já existentes, mas contribuirá para a produção de novos.

Demo (2007) lembra a valorização do conhecimento popular em pesquisas participantes em que se almeja a autonomia dos sujeitos, mas chama a atenção para o fato de que, assim como a comunidade não tem todas as respostas, os pesquisadores também não, ou seja, deve-se reconhecer a relevância tanto do conhecimento científico, como do conhecimento popular, pois estes não são concorrentes, mas sim complementares. Em adição, Meyer et al. (2006, p. 1340) afirmam que

[...] a intencionalidade de construir estratégias educativas que permitam investir em possibilidades de transformação das condições de vida, nas quais crenças, hábitos e comportamentos ganham sentido, demanda aprender, compreender e dialogar com a multiplicidade de aspectos que modulam as crenças, os hábitos e os comportamentos dos indivíduos e grupos com os quais interagimos.

Essa interação e troca de saberes favorece ainda o fortalecimento dos indivíduos como sujeitos sociais e a tomada de consciência, pois, ao interagir com os pesquisadores e com outras pessoas que vivenciam situações semelhantes, as representações desses sujeitos são reconhecidas ou transformadas.

Em concordância, Gil (2005) considera que, por meio desse processo de pesquisa e intervenção, as pessoas envolvidas em determinada problemática e que participam da busca de soluções beneficiam-se não só com os resultados da pesquisa, mas também durante seu desenvolvimento, o que é próprio da metodologia da pesquisa-ação. E como destaca Barbier (2002), ela requer uma reflexão constante sobre a ação em todas as etapas do processo. 
Assim, ao se envolverem em uma pesquisa-ação, os atores sociais, por meio de reflexão crítica sobre a realidade em que se inserem, começam a se questionar sobre suas práticas e a formular perguntas que os auxiliarão na resolução de seus problemas. No decorrer desse processo constroem-se não só conhecimentos individuais ou coletivos, mas também novas habilidades e atitudes que propiciarão a ressignificação de valores e a transformação de situações indesejadas.

\section{Pesquisa-ação e educação: um diálogo possível e relevante}

Para esta reflexão, propõe-se inicialmente uma análise do pensamento de dois autores para o enfrentamento da atual crise socioambiental, política, econômica e cultural. Para Santos (2001), há apenas uma saída: "reinventar o futuro, abrir um novo horizonte de possibilidades, cartografado por alternativas radicais às que deixaram de ser" (p. 322). Já Guimarães (2004) utiliza-se de uma metáfora onde "o rio representa a sociedade; a sua correnteza, o paradigma dominante; e o curso do rio, o processo histórico. Para mudarmos o rio (sociedade), precisamos interferir na correnteza (paradigmas) do seu curso (processo histórico)" (p. 29). Esse autor lança ainda o seguinte questionamento: "como fazer se não quero ser carregado pela correnteza?" (p. 30). Neste caso, sugere como uma das alternativas a criação de uma contracorrenteza, por meio de um movimento coletivo de resistência.

Assim, considera-se que a educação, como um processo planejado e participativo de reflexão e ação, pode oferecer subsídios para que os grupos sociais "nadem contracorrenteza" e "reinventem o futuro", atuando na busca de soluções e na tomada de decisões sobre os problemas que lhes dizem respeito, satisfazendo não apenas suas necessidades, mas também seus anseios diversos. E, neste contexto, a pesquisaação tem se mostrado como uma alternativa metodológica eficaz para tal finalidade.

Desde a sua origem, identifica-se a pesquisa-ação como sendo desenvolvida não só na educação, mas em diversas outras áreas do conhecimento, tais como: administração, desenvolvimento comunitário, mudança organizacional, práticas políticas, agricultura, negócios bancários, saúde, serviço social, geração de tecnologia, entre outras (TRIPP, 2005; THIOLLENT, 2011).

Objetivando neste texto destacar sua aplicação e contribuições para a área da educação, por meio de revisão bibliográfica, procurou-se identificar as dissertações de mestrado e teses de doutorado desenvolvidas nas universidades estaduais paulistas Universidade de São Paulo (USP), Universidade Estadual Paulista "Julio de Mesquita Filho" (Unesp) e Universidade Estadual de Campinas (Unicamp) - que fizeram uso da metodologia da pesquisa-ação, no período de 1990 a 2010. A busca foi realizada nas Bibliotecas Digitais de Teses e Dissertações (Dedalus/USP, Athena/Unesp, Nou-Rou/ Unicamp) das respectivas universidades, cujos trabalhos encontravam-se disponíveis. 
O critério-chave para inclusão foi possuir no resumo a expressão "pesquisa-ação" e, a partir da análise deste, identificá-lo como um estudo que fez uso desta metodologia e que se relacionava à educação, seja como objeto de análise ou como processo e/ou produto da investigação. Ressalta-se, portanto, que os resultados desta busca refletem um panorama bastante específico, mas que contribuem para fortalecer a discussão aqui proposta.

Foram encontrados 131 trabalhos na USP, 50 na Unesp ${ }^{3}$ e 68 na Unicamp, totalizando 249 estudos que adotaram a metodologia da pesquisa-ação no período considerado. Os quadros 1 e 2 a seguir apresentam respectivamente o número de trabalhos por faculdade e o número de trabalhos defendidos por ano, no período considerado.

\section{Quadro 1}

Número de trabalhos (dissertações e teses) por faculdade, desenvolvidos por meio da pesquisa-ação, na USP, Unesp e Unicamp, no período de 1990 a 2010

\begin{tabular}{|c|c|c|}
\hline Universidade & Faculdade & $\begin{array}{l}\text { Número de } \\
\text { Trabalhos }\end{array}$ \\
\hline \multirow{19}{*}{ USP } & Faculdade de Educação & 54 \\
\hline & Escola de Enfermagem de Ribeirão Preto & 35 \\
\hline & Escola de Enfermagem & 8 \\
\hline & Escola de Comunicação e Artes & 8 \\
\hline & Faculdade de Saúde Pública & 6 \\
\hline & Faculdade de Filosofia, Letras e Ciências Humanas & 4 \\
\hline & Escola de Educação Física e Esporte & 2 \\
\hline & Escola de Engenharia e São Carlos & 2 \\
\hline & Escola Superior de Agricultura Luiz de Queiroz & 2 \\
\hline & Faculdade de Medicina & 1 \\
\hline & Escola de Educação Física e Esporte de Ribeirão Preto & 1 \\
\hline & Instituto de Biociências & 1 \\
\hline & Faculdade de Arquitetura e Urbanismo & 1 \\
\hline & Programa de Pós-Graduação em Ciência Ambiental (Procam) & 1 \\
\hline & $\begin{array}{l}\text { Programa de Pós-Graduação em Integração da América Latina } \\
\text { (Prolam) }\end{array}$ & 1 \\
\hline & Instituto de Física & 1 \\
\hline & Escola Politécnica & 1 \\
\hline & Instituto de Psicologia & 1 \\
\hline & Faculdade de Economia e Administração & 1 \\
\hline
\end{tabular}


Pesquisa-ação e educação: compartilhando princípios na construção de conhecimentos...

\begin{tabular}{|c|c|c|}
\hline Universidade & Faculdade & $\begin{array}{l}\text { Número de } \\
\text { Trabalhos }\end{array}$ \\
\hline \multirow{12}{*}{ Unesp } & Faculdade de Filosofia e Ciências, Marília & 16 \\
\hline & Instituto de Biociências, Rio Claro & 10 \\
\hline & Faculdade de Ciências e Tecnologia, Presidente Prudente & 5 \\
\hline & Instituto de Artes, São Paulo & 4 \\
\hline & $\begin{array}{l}\text { Instituto de Biociências, Letras e Ciências Exatas, São José do Rio } \\
\text { Preto }\end{array}$ & 3 \\
\hline & Faculdade de Ciências e Letras, Araraquara & 2 \\
\hline & Faculdade de Ciências, Bauru & 2 \\
\hline & Faculdade de Ciências e Letras, Assis & 2 \\
\hline & Instituto de Geociências e Ciências Exatas, Rio Claro & 2 \\
\hline & Faculdade de Medicina, Botucatu & 2 \\
\hline & Faculdade de Engenharia, Guaratinguetá & 1 \\
\hline & Faculdade de Ciência Humanas e Sociais, Franca & 1 \\
\hline \multirow{7}{*}{ Unicamp } & Faculdade de Educação & 28 \\
\hline & Instituto de Estudos da Linguagem & 16 \\
\hline & Faculdade de Educação Física & 11 \\
\hline & Instituto de Geociências & 5 \\
\hline & Instituto de Artes & 4 \\
\hline & Faculdade de Ciências Médicas & 3 \\
\hline & Instituto de Biologia & 1 \\
\hline \multicolumn{2}{|r|}{ TOTAL } & 249 \\
\hline
\end{tabular}

\section{Quadro 2}

Número de trabalhos (dissertações e teses) desenvolvidos com pesquisa-ação na USP, Unesp e Unicamp defendidos por ano, no período de 1990 a 2010

\begin{tabular}{|c|c|c|c|c|c|c|c|c|c|c|c|}
\hline & \multicolumn{11}{|c|}{ Ano } \\
\hline & 1990 & 1991 & 1992 & 1993 & 1994 & 1995 & 1996 & 1997 & 1998 & 1999 & 2000 \\
\hline \multirow{3}{*}{$\begin{array}{l}\mathrm{N}^{0} \text { de } \\
\text { trabalhos }\end{array}$} & 1 & 1 & 0 & 1 & 0 & 6 & 5 & 3 & 6 & 6 & 11 \\
\hline & \multicolumn{11}{|c|}{ Ano } \\
\hline & 2001 & 2002 & 2003 & 2004 & 2005 & 2006 & 2007 & 2008 & 2009 & 2010 & \\
\hline $\begin{array}{c}\mathrm{N}^{\circ} \text { de } \\
\text { trabalhos }\end{array}$ & 19 & 9 & 14 & 11 & 29 & 21 & 35 & 28 & 21 & 22 & \\
\hline
\end{tabular}


Estudo semelhante, porém de maior abrangência, realizado por Molina (2007), identificou 236 trabalhos defendidos (dissertações e teses) nos Programas de PósGraduação em Educação das instituições de ensino superior no Brasil, no período de 1971 a 2002. O autor ressalta que, entre 1972 e 1985, houve extensos espaços de tempo sem nenhuma produção, totalizando neste intervalo apenas quatro estudos; entre 1988 e 1992, apesar de ainda modesta, a produção aumentou para 16 estudos; e que, a partir de 1993, a pesquisa-ação se consolidou como uma tendência emergente nas pesquisas em Educação, sendo que deste ano até 1996 foram realizados 48 estudos. No último período considerado pelo autor, de 1997 a 2002, foram identificados 168 trabalhos.

Resultados da análise realizada por Jesus (2002), sobre pesquisas produzidas em salas de aula nas quatro primeiras séries do ensino fundamental, confirmam essa tendência, pois no período entre 1989-1999 a pesquisa-ação foi a metodologia mais utilizada. Em outro estudo, empreendido por Fernandes (2009), com foco no Ensino de Ciências, a pesquisa-ação também figurou como uma das metodologias mais presentes no período de 1972 a 2005, e sua relevância é reforçada pela autora para a melhoria do ensino e desenvolvimento profissional do professor.

Para efeito de comparação entre as pesquisas anteriormente citadas e o panorama apresentado no presente texto, apesar de representarem intervalos de tempo e universos de busca distintos, fica evidente a tendência de emergência de estudos com pesquisa-ação, pois, conforme o quadro 2 apresentado, no primeiro intervalo de tempo, de 1990 a 2000, foram identificados quarenta trabalhos, e de 2001 a 2010, esse número aumentou para 209.

A opção por não considerar na construção deste panorama sobre a pesquisa-ação apenas os Programas de Pós-Graduação em Educação justifica-se pela relevância desta metodologia em estudos de caráter interdisciplinar, onde o componente educacional se faz presente de diversas maneiras, como objeto de análise ou como parte do processo de intervenção, conforme abordado anteriormente. E, de fato, foram encontradas inúmeras dissertações e teses defendidas em instituições de ensino superior na área da saúde, das ciências naturais, entre outras, conforme quadro 1, mas que também tratavam de assuntos ligados à temática educacional - como, por exemplo, a formação do profissional de enfermagem - ou que objetivavam desenvolver uma intervenção educativa como parte do processo de investigação, o que é próprio da pesquisa-ação.

Assim, dentre os temas mais abordados nos trabalhos identificados destacaram-se: reflexões sobre a formação profissional e os processos de ensino-aprendizagem; avaliação e/ou implementação do uso de novos materiais pedagógicos; educação ambiental; educação e promoção da saúde; educação inclusiva; relações entre a 
comunidade escolar (alunos, professores, pais); e vulnerabilidade social associada à sexualidade, uso de drogas e/ou violência.

Percebe-se que a problemática a ser investigada e compreendida em torno destes temas é muitas vezes de natureza complexa, pois além de envolverem aspectos diversos como sociais, políticos, éticos, culturais, ambientais, econômicos etc., são marcados por conflitos de interesses. E, para esses casos, o uso de métodos de pesquisa distintos dos já consagrados clássicos ou tradicionais tem se mostrado bastante eficaz. Nesse sentido, a pesquisa-ação se propõe a ir além da busca de respostas para os problemas em estudo, avançando em direção ao enfrentamento destes no decorrer do seu desenvolvimento. Em adição, considera-se que, por fundamentar-se no diálogo de saberes entre os diversos sujeitos envolvidos e caracterizar-se como um sistema metodológico aberto em constante construção e reconstrução, possibilitando a combinação de instrumentos de pesquisa dialéticos e não dialéticos, pode-se dizer que esse processo de compreensão e enfrentamento de problemas de natureza complexa é facilitado.

Em concordância, a viabilidade da pesquisa-ação é da mesma maneira enfatizada por outros autores, no sentido de que, ao envolver grupos sociais na resolução de seus problemas, permite integrar ensino, pesquisa e extensão. Além disso, ao se analisar princípios norteadores da educação, torna-se clara a pertinência de abordagens e estratégias metodológicas que superem a lógica tradicional (SANTOS, 2004; TOZONI-REIS, 2007).

Neste contexto, ao destacar seu caráter reflexivo, mobilizador, gerador de conhecimentos interdisciplinares e de soluções coletivas, a pesquisa-ação aplicada à educação mostra-se com forte potencial de contribuição em processos de transformação das práticas institucionais, bem como no desenvolvimento da cidadania e do empoderamento, elementos essenciais para a mediação de situações de conflito.

Manzano (2009), ao analisar uma experiência com pesquisa-ação sobre diversidade e violência na escola com foco na formação de professores, reconheceu a criação de um espaço de escuta e a construção coletiva de ideias plurais, onde o professor passou de objeto de análise para sujeito da análise e reflexão do seu próprio cotidiano, facilitando, portanto, o enfrentamento da problemática em questão sem pré-julgamentos, mas deixando a experiência ser revelada por si.

Outro paralelo a ser estabelecido entre a pesquisa-ação e a educação é que ambos os processos devem ser pensados e constantemente reformulados de forma a atender às necessidades coletivas, conforme propõe, inclusive, o espiral cíclico de Lewin: planejamento, ação e encontro de fatos. Malagodi (2009) reforça essa ideia ao investigar o percurso de uma ação em educação ambiental, pois sugere a 
pesquisa-ação (proposta por Kurt Lewin e na perspectiva da filosofia da práxis de René Barbier) como facilitadora de intervenções sociais e da integração entre teoria e prática, de forma a atender interesses coletivos.

Identifica-se, portanto, que, nos processos de pesquisa-ação, tanto a pesquisa como a ação (educativa e social) são igualmente importantes e, na opinião de Tozoni-Reis (2007), o abandono desta perspectiva tem se mostrado como um dos mais frequentes equívocos no uso desta metodologia.

Dentre os resultados da revisão bibliográfica, merece destaque ainda a identificação de diversas modalidades/abordagens de pesquisa-ação, assim denominadas: "pesquisa-ação participante"; "pesquisa-ação integral e sistêmica"; "pesquisa-ação colaborativa"; "pesquisa-ação colaborativa/comunicacional"; "pesquisa-ação existencial"; "pesquisa-ação crítico-colaborativa"; e "pesquisa-ação emancipatória". O quadro 3 a seguir traz esclarecimentos sobre cada uma delas, segundo autores dos trabalhos e/ou referências por eles adotadas.

\section{Quadro 3}

Modalidades/abordagens de pesquisa-ação identificadas entre os trabalhos (dissertações e teses) desenvolvidos na USP, Unesp e Unicamp, defendidos no período de 1990 a 2010, e trechos explicativos para cada uma delas, segundo autores dos trabalhos e/ou referências por eles adotadas.

\begin{tabular}{|l|l|}
\hline $\begin{array}{l}\text { Modalidades/abordagens } \\
\text { de pesquisa-ação }\end{array}$ & \multicolumn{1}{c|}{$\begin{array}{c}\text { Trechos explicativos, segundo autores dos trabalhos e/ou } \\
\text { referências por eles adotadas }\end{array}$} \\
\hline $\begin{array}{l}\text { Pesquisa-ação } \\
\text { participante }\end{array}$ & $\begin{array}{l}\text { "A escolha metodológica da minha pesquisa é embasada na proposta } \\
\text { de Orlando Fals Borda, denominada por ele de pesquisa-ação-partici- } \\
\text { pante, tendo como foco a "investigação participativa", propondo o tra- } \\
\text { balho político libertador como critério central da criação desta nova } \\
\text { ciência do homem" (Turina, 2008, p. 12). }\end{array}$ \\
\hline $\begin{array}{l}\text { Pesquisa-ação integral } \\
\text { e sistêmica }\end{array}$ & $\begin{array}{l}\text { “O universo de estudo desta pesquisa configura-se em torno do pro- } \\
\text { cesso de elaboração e construção da Agenda 21 Escolar de Embu das } \\
\text { Artes, cujo percurso pautou-se pela adoção de técnicas e estratégias } \\
\text { da pesquisa-ação integral e sistêmica, de André Morin (2004), buscando } \\
\text { o envolvimento dos participantes do processo como coautores do co- } \\
\text { nhecimento e práticas engajadas, numa abordagem interativa, colabo- } \\
\text { rativa" (Franco, 2010, p. 25). }\end{array}$ \\
\hline $\begin{array}{l}\text { Pesquisa-ação } \\
\text { colaborativa }\end{array}$ & $\begin{array}{l}\text { "A compreensão de todo o processo desta pesquisa-ação de natureza } \\
\text { colaborativa se baseia nas relações entre cada um dos participantes, } \\
\text { isto é, (professora-pesquisadora, alunos, professores coordenadores, } \\
\text { direção) em que o conceito de "colaboração" baseia-se na igualdade } \\
\text { de oportunidades dos participantes da interação em colocar em dis- } \\
\text { cussão sentidos/significados, valores e conceitos que vêm embasando } \\
\text { suas ações, escolhas, dúvidas e discordâncias" (Dias, 2003, p. 54). }\end{array}$ \\
\hline
\end{tabular}




\begin{tabular}{|c|c|}
\hline $\begin{array}{l}\text { Modalidades/abordagens } \\
\text { de pesquisa-ação }\end{array}$ & $\begin{array}{c}\text { Trechos explicativos, segundo autores dos trabalhos e/ou } \\
\text { referências por eles adotadas }\end{array}$ \\
\hline $\begin{array}{l}\text { Pesquisa-ação } \\
\text { colaborativa/ } \\
\text { comunicacional }\end{array}$ & $\begin{array}{l}\text { "Colaborativa, pelo fato de ter sua origem em necessidade sentida } \\
\text { pela SME de Mogi das Cruzes, solicitando cursos e projetos de for- } \\
\text { mação contínua de professores, ratificada pela adesão voluntária de } \\
\text { professores das escolas que tiveram a liberdade de atender ou não a } \\
\text { um convite para participação em cursos e projetos disponibilizados. } \\
\text { E ainda por ter se articulado, ao longo do seu desenvolvimento, com } \\
\text { outras instituições. Comunicacional, porque realizada com a partici- } \\
\text { pação de sujeitos que vivenciaram os problemas focalizados pela } \\
\text { pesquisa e que em conjunto com o pesquisador vêm desvendando as } \\
\text { condições que consideram problemáticas e cooperam na construção } \\
\text { de críticas construtivas, transformadoras das práticas consideradas } \\
\text { (Fernandes, 2009, p. 89). }\end{array}$ \\
\hline Pesquisa-ação existencial & $\begin{array}{l}\text { "O pesquisador na pesquisa-ação é, portanto, o sujeito - autor de } \\
\text { sua prática e de seu discurso; a pesquisa que realiza é compartilha- } \\
\text { da com outros/outro, em um grupo em que interagem os conflitos e } \\
\text { imprevistos, no qual se admite a incompletude de cada um. Dessa } \\
\text { interação emerge um saber e a possibilidade de apropriação e, por } \\
\text { conseguinte, da autorização como fundamento da autoridade mo- } \\
\text { ral docente. A esse tipo de pesquisa, Barbier (2002) classifica como } \\
\text { pesquisa-ação existencial e se distingue da pesquisa-ação realizada } \\
\text { apenas com a finalidade de implantar programas práticos" (Acker, } \\
\text { 2008, p. 30). }\end{array}$ \\
\hline $\begin{array}{l}\text { Pesquisa-ação } \\
\text { crítico-colaborativa }\end{array}$ & $\begin{array}{l}\text { "Trabalhar dentro de uma perspectiva metodológica fundada na } \\
\text { pesquisa-ação crítico-colaborativa pressupõe, segundo Franco (2005), um } \\
\text { ambiente onde a pesquisa é desencadeada pela busca de transforma- } \\
\text { ção solicitada pelo grupo pesquisado, sendo alicerçada por um pensa- } \\
\text { mento crítico coletivo, visando a emancipação dos sujeitos e das con- } \\
\text { dições consideradas opressivas pelo grupo" (Rodrigues, 2008, p. 102). }\end{array}$ \\
\hline $\begin{array}{l}\text { Pesquisa-ação } \\
\text { emancipatória }\end{array}$ & $\begin{array}{l}\text { "A pesquisa-ação emancipatória, por sua vez, ocorre quando um grupo } \\
\text { de praticantes assume coletivamente a responsabilidade do desenvol- } \\
\text { vimento/transformação da prática, considerando-a social e historica- } \\
\text { mente construída. Aqui, o próprio grupo de professores assume a res- } \\
\text { ponsabilidade de emancipar-se das amarras da alienação, da falta de } \\
\text { autorrealização e da injustiça social. Cabe sempre ao grupo promover } \\
\text { e desenvolver seu próprio trabalho" (Sborquia, 2008, p. 137). }\end{array}$ \\
\hline
\end{tabular}

Como se percebe, diferentes "classificações" para a pesquisa-ação consideram aspectos como a sua intencionalidade, nível de envolvimento dos sujeitos, origem das necessidades, natureza da intervenção, entre outros; aspectos estes que, muitas vezes, se sobrepõem, como aqueles relacionados aos princípios norteadores, entre eles a reflexão e o diálogo de saberes, ou ainda referentes à sua organização como um sistema aberto e cíclico. Assim, percebe-se que uma pesquisa-ação classificada como "emancipatória" pode também ser "crítico-colaborativa", e vice-versa. 
Para Franco (2005), nas últimas décadas, a pesquisa-ação tem sido utilizada de diversas maneiras, constituindo um "vasto mosaico de abordagens teórico-metodológicas", e que, "muitas vezes se operacionalizam na práxis investigativa, sem a necessária explicitação de seus fundamentos teóricos, gerando inconsistências entre teoria e método e comprometimentos à validade científica dos estudos" (p. 485). Tripp (2005) ressalta que, devido à sua popularidade, a pesquisa-ação tem sido aplicada de maneira vaga a qualquer tentativa de investigação ou melhoria da prática. Monteiro et al. (2000) alertam ainda para a tendência da pesquisa-ação tornar-se um modismo, pois afirmam que novas teorias e práticas são muitas vezes recebidas sem muita crítica e, como consequência, recaem sobre a banalidade.

Assim, considera-se fundamental a realização de estudos que analisem princípios teóricos e práticas de metodologias como a pesquisa-ação, de forma a contribuir para seu constante aprimoramento.

\section{Considerações finais}

Com base nas reflexões aqui propostas e argumentos apresentados, evidencia-se o uso da pesquisa-ação como extremamente adequada na área da educação, já que ambos os processos objetivam estimular a autonomia dos sujeitos, por meio da construção dialógica de saberes, o desenvolvimento de práticas cidadãs e a busca de soluções para os problemas de forma participativa.

Conclui-se ainda que, nas últimas décadas, a pesquisa-ação tem sido utilizada junto a diversos temas, baseando-se em uma grande variedade de representações e abordagens teórico-metodológicas. Apesar disso, carrega o objetivo comum de se consolidar como uma nova linha de pensamento e de enfrentamento dos problemas que ultrapasse os limites acadêmicos das pesquisas clássicas e tradicionais, aproximando os diversos atores sociais (sujeitos do problema, pesquisadores e tomadores de decisão) e contribuindo para a implementação de políticas públicas que sustentam, inclusive, a educação.

\section{Notas}

1. A obra original é de 1977, mas só em 1985 foi traduzida e publicada no Brasil: Pesquisa-ação na instituição educativa (Rio de Janeiro: Zahar).

2. A primeira edição do livro Metodologia da pesquisa-ação, de Michel Thiollent, é de 1985. Atualmente, está na $18^{\underline{a}}$ edição.

3. Na Biblioteca Digital de Teses e Dissertações da Unesp (Athena) foram encontrados trabalhos apenas a partir de 2001 . 


\section{Referências}

ACKER, M.T.V.V. A reflexão e a prática docente: considerações a partir de uma pesquisa-ação. 2008. Tese (Doutorado em Educação) - Faculdade de Educação, Universidade de São Paulo, São Paulo.

ADELMAN, C. Kurt Lewin and the origins of action research. Educational Action Research, Wallingford, v.1, n. 1, p. 7-24, 1993.

BARBIER, R. A pesquisa-ação. Brasília, DF: Plano, 2002.

CARR, W.; KEMMIS, S. Becoming critical: education, knowledge and action research. London; Philadelphia: Palmer, 1986.

COREY, S. Esperar? Ou começar a saber! In: MORSE, W.C.; WINGO, G. M. (Org.). Leituras de psicologia educacional.Trad. de Dante Moreira Leite. 2. ed. São Paulo: Nacional, 1979. p. 296-302. (Atualidades Pedagógicas, v. 93).

COSTA, M.C.V. A caminho de uma pesquisa-ação crítica. Educação \& Realidade, Porto Alegre, v. 16, n. 2, p. 47-53, jul./dez. 1991.

DEMO, P. Pesquisa-participante: usos e abusos. In: TOZONI-REIS, M.F.C. (Org.). A pesquisa-ação-participativa em educação ambiental: reflexões teóricas. São Paulo: Annablume, 2007. p. 57-81.

DIAS, E. Falar ou não falar? Eis a questão. 2003. Dissertação (Mestrado) - Instituto de Biociências, Letras e Ciências Exatas, Universidade Estadual Paulista "Júlio de Mesquita Filho", São José do Rio Preto.

EL ANDALOUSSI, K. Pesquisas-ações: ciências, desenvolvimento, democracia. São Carlos: Edufscar, 2004.

FALS BORDA, O. Conocimiento y poder popular: lecciones con campesinos de Nicaragua, México y Colombia. Bogotá: Siglo XXI, 1986.

FERNANDES, I.M.B.A. Música na escola: desafios e perspectivas na formação contínua de educadores da rede pública. 2009. Tese (Doutorado em Educação) - Faculdade de Educação, Universidade de São Paulo, São Paulo.

FERNANDES, R.C.A. Tendências da pesquisa acadêmica sobre o ensino de ciências nas séries iniciais da escolarização (1972-2005). 2009. Dissertação (Mestrado em Educação) - Faculdade de Educação, Universidade Estadual de Campinas, Campinas.

FLICKER, S. Who benefits from community-based participatory research?: a case study of the positive youth project. Health Education \& Behavior, v. 35, n. 1, p. 70-86, feb. 2008. 
FRANCO, M.A.S. Pedagogia da pesquisa-ação. Educação E Pesquisa, São Paulo, v. 31, n. 3, p. 483-502, set./dez. 2005.

FRANCO, M.I.G.C. Educação ambiental e pesquisa-ação participante: registro analíticocrítico de uma práxis educativa. 2010. Tese (Doutorado em Educação) - Faculdade de Educação, Universidade de São Paulo, São Paulo.

GIL, A.C. Métodos e técnicas de pesquisa em educação ambiental. In: PHILIPPI JUNIOR., A; PELICIONI, M.C.F. (Org.). Educação ambiental e sustentabilidade. Barueri: Manole, 2005. p. 577-598. (Coleção Ambiental, 3).

GIOVANNI, L.M. Didática da pesquisa-ação: análise de uma experiência de parceria entre universidade e escolas públicas de primeiro e segundo graus. 1994. Tese (Doutorado em Educação) - Faculdade de Educação, Universidade de São Paulo, São Paulo.

GOYETTE, F.; LESSARD-HÉRBET, M. La recherché-action, ses fonctions, ses fondements, son instrumentation. Montréal: Presses de l'Université du Quebéc, 1993.

GUIMARÃES, M. Educação ambiental crítica. In: LAYRARGUES, P.P. (Org.). Identidades da educação ambiental brasileira. Brasília, DF: Ministério do Meio Ambiente; Diretoria de Educação Ambiental, 2004. p. 25-34.

JESUS, L.F.O. A sala de aula: uma análise de pesquisas produzidas na década de 19891999. 2002. Dissertação (Mestrado em Educação) - Faculdade de Educação, Universidade de São Paulo, São Paulo.

LEBEL, J. Health: an ecosystem approach. Canada: International Development Research Centre, 2003.

LEWIN, K. Action research and minority problems. Journal of Social Issues, Malden, v. 2, n. 2, p. 34-36, 1946.

LIST, D. Action research cycles for multiple futures perspectives. Futures, Guildford, v. 38, p. 673-684, 2006.

MALAGODI, M.A.S. Entre as palavras e a intervenção social: análise de uma trajetória individual em uma ação de educação ambiental interpretada a partir da filosofia da práxis. 2009. Tese (Doutorado em Psicologia) - Instituto de Psicologia, Universidade de São Paulo, São Paulo.

MANZANO, C.S. Deslocamentos discursivos sobre a diversidade: análise de uma experiência de pesquisa-ação formativa com professores. 2009. Dissertação (Mestrado em Educação) - Faculdade de Educação, Universidade de São Paulo, São Paulo.

MEYER, D.E.E. et al. "Você aprende. A gente ensina?": interrogando relações entre 
educação e saúde desde a perspectiva da vulnerabilidade. Cadernos de Saúde Pública, Rio de Janeiro, v. 22, n. 6, p. 1335-1342, 2006.

MOLINA, R. A pesquisa-ação/investigação-ação no Brasil: mapeamento da produção (1966-2002) e os indicadores internos da pesquisa-ação colaborativa. 2007. Tese (Doutorado em Educação) - Faculdade de Educação, Universidade de São Paulo, São Paulo.

MONTEIRO, S.B. et al. Considerações críticas sobre a concepção de pesquisaação em Joe Kincheloe. 2000. Disponível em: <www.anped.org.Br/reuniões/23/ textos/0406p.pdf>.

MORIN, A. Pesquisa-ação integral e sistêmica: uma antropopedagogia renovada. Rio de Janeiro: DP\&A, 2004.

PAHL WOST, C.; HARE, M. Processes of social learning in integrated resources management. Journal of Community and Applied Psychology, New York, v. 14, p. 193206, 2004.

PIMENTA, S.G. Pesquisa-ação crítico-colaborativa: construindo seu significado a partir de experiências com a formação docente. Educação \& Pesquisa, São Paulo, v. 31, n. 3, p. 521-539, set./dez. 2005.

RAVETZ, J. The post-normal science of precaution. Futures, Guildford, v. 36, p. 347357, 2004.

RODRIGUES, A.C.L. Jogos de construção nas aulas de educação física: alternativa pedagógica para aquisição de competências leitora e escritora. 2008. Dissertação (Mestrado em Educação) - Faculdade de Educação, Universidade de São Paulo, São Paulo.

SANTOS, B.S. Pela mão de Alice: o social e o político na pós-modernidade. São Paulo; Cortez; Campinas: Editores Associados, 2001.

SANTOS, B.S. A universidade no século XXI: para uma reforma democrática e emancipatória da Universidade. São Paulo: Cortez, 2004.

SBORQUIA, S.P. Da formação e desenvolvimento profissional do professor de educação física a inovação educativa. 2008. Tese (Doutorado) - Faculdade de Educação Física, Universidade Estadual de Campinas, Campinas.

THIOLLENT, M. Metodologia da pesquisa-Ação. 18. ed. São Paulo: Cortez, 2011.

THIRION, A.M. Tendances actuelles de la recherche-action. Examen critique. Liège: Université de Liège Bélgica, 1980. 
TOZONI-REIS, M.F.C. A pesquisa-ação-participativa e a educação ambiental: uma parceria construída pela identificação teórica e metodológica. In: TOZONI-REIS, M.F.C. (Org.). A Pesquisa-ação-participativa em educação ambiental: reflexões teóricas. São Paulo: Annablume, 2007. p. 121-161.

TRIPP, D. Pesquisa-ação: uma introdução metodológica. Educação \& Pesquisa, São Paulo, v. 31, n. 3, p. 443-466, set./dez. 2005.

TURINA, M.F.P. O fazer metodológico na educação de jovens e adultos: a prática no Projeto Educativo de Integração Social - Peis. 2008. Dissertação (Mestrado em Educação) - Faculdade de Educação Física, Universidade Estadual de Campinas, Campinas.

ZUNIIGA, R. La recherche-action et le controle du savoir. Revue Internationale d'Action Communautaire, Lorraine, v. 45, n. 5, p. 35-44, 1981.

Recebido em 12 de setembro de 2011.

Aprovado em 9 de outubro de 2012. 